\title{
Optimal management of saline water tables in irrigated regions
}

Timothy K. Gates $\square$ Mark E. Grismer

\section{A computer model incorporates uncertainties about water tables and aquifers into irrigation management.}

L Large parts of California's San Joaquin Valley are afflicted with waterlogging and salinity due to perched saline water tables. The survival of agriculture as an economically profitable and environmentally acceptable venture in these areas will require careful management of irrigation and drainage on a regional scale.

The effect of regional irrigation and drainage practices on crop production and the environment is subject to considerable uncertainty because of variability of water table aquifer properties throughout the region and during the year. Incorporation of a simulation model, which accounts for this variability, into improved management schemes allows uncertainties about aquifer behavior to be taken into account in the decision-making process. Such an approach constitutes a significant advance in operations research on aquifer management. Moreover, it addresses a question that bears heavily on the management of resources for the future of agriculture in the valley: How much confidence can we place in our predictions of long-term groundwater behavior and its impact on regional crop production?

The proposed approach considers uncertainty associated with regional-scale variability in aquifer properties and its effect on management decisions regarding control of artificial drainage and irrigation applications.

\section{Model formulation}

The system under consideration was formulated as a region, about 10 square miles in area, of intense irrigated agriculture underlain by a high saline water table. A cross-section through the region (fig. 1) shows a perched water table aquifer bounded on the bottom by dense clay through which leakage occurs to an underlying aquifer. The water table receives seepage from excess irrigation that leaches the root zone. Saline water may flow upward from the water table to supply evapotranspiration (ET) demand. Perched water may be drained by artificial drainage, and lateral subsurface flow may occur across the thickness of the aquifer. Finally, at the regional scale, the soil is considered to vary in hydraulic conductivity, porosity, and specific yield.

Proper management of perched saline water tables to minimize detrimental effects on crop production depends on hydrogeologic properties that govern behavior of shallow aquifers on a regional scale. The average crop yield over a region is directly influenced by the distribution of soil salinity and water table depth. These processes are, in turn, affected by seepage resulting from excess irrigation, artificial drainage, and solution transport in the water table aquifer.

Groundwater flow and solute transport depend on the site and seasonal variation of aquifer properties, boundary conditions, and the amount and location of seepage and evapotranspiration. These factors combine to make up complex systems that defy attempts to describe them precisely. Even the most ambitious efforts at field data collection result in meager and possibly inaccurate information. This uncertainty about aquifer properties has led researchers to the use of statistical descriptions. Thus, rather than working with actual variation in properties, researchers attempt to describe and preserve the statistical properties of that variation. The science of stochastic (literally, educated guesswork) processes provides a framework for such a description.

In the past decade, many investigators have adopted a stochastic approach for modeling groundwater flow and solute transport. Uncertainties in salinity concentration and migration, and water table depths, can be explicitly considered in these models. Model outputs of the random nature of regional groundwater phenomena permit impacts on regional crop production to be analyzed statistically. Further development in regional modeling requires incorporation of probability simulation models into schemes designed to help managers maintain acceptable agricultural production and environmental quality.

It was assumed in this study that the objective of planners in management of saline water tables in specific regions of
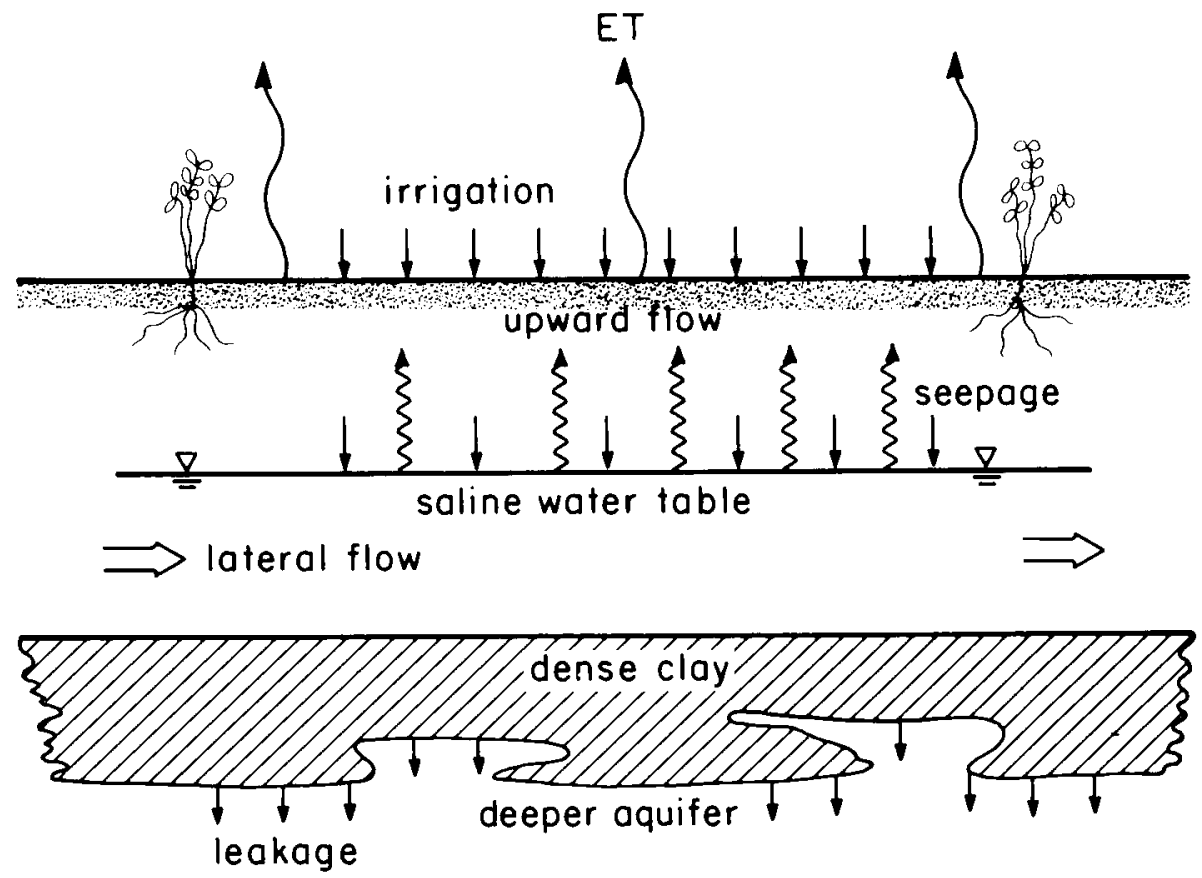

Fig. 1. Cross-sectional depiction of regional aquifer system used in this study. 


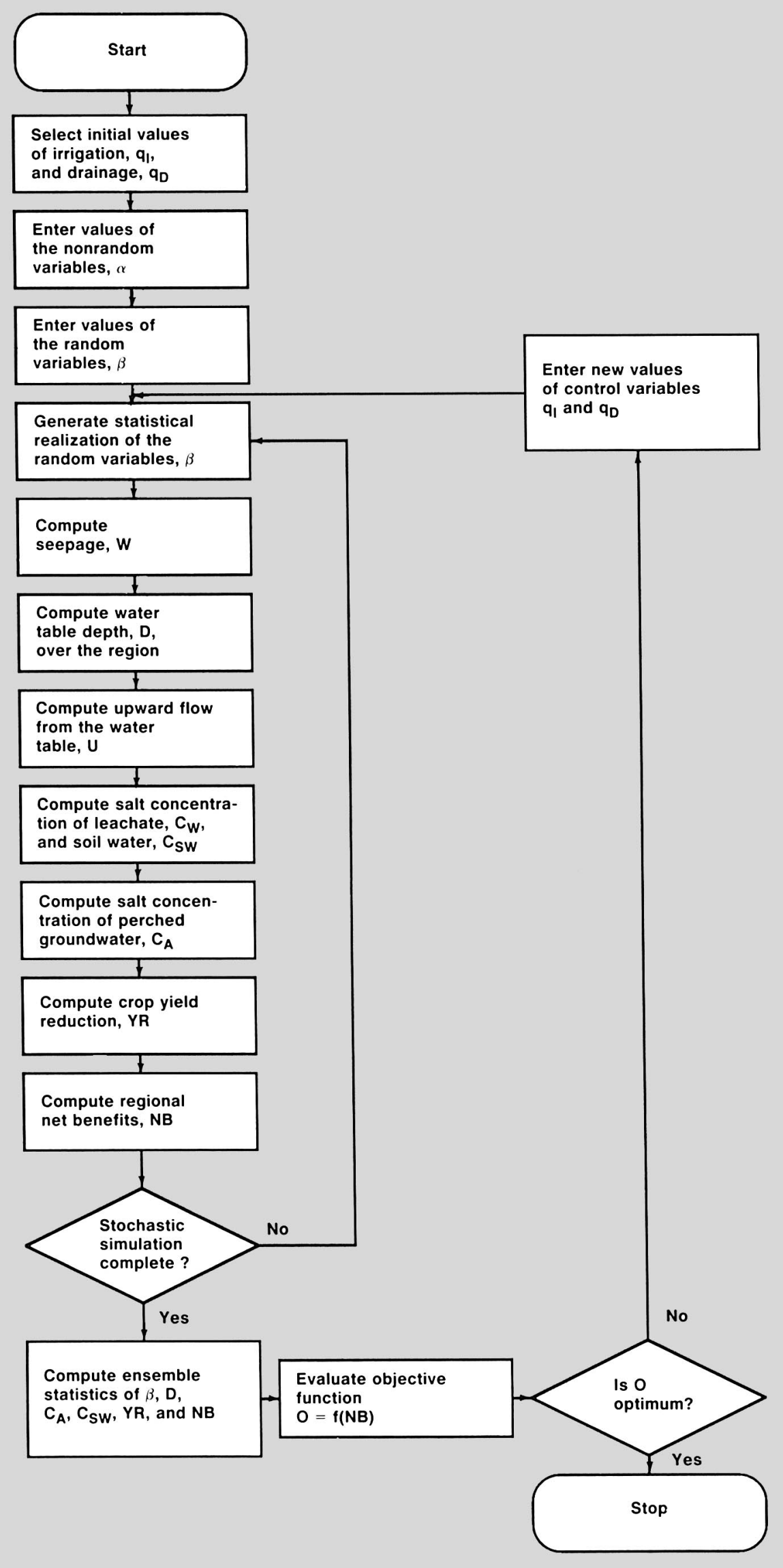

Fig. 2. General flow chart of computational procedure. the San Joaquin Valley is to obtain maximum net economic benefits from agricultural production in a manner that respects the environment. This goal can be accomplished by selection of optimum irrigation and subsurface drainage volumes.

\section{Optimization procedure}

The significance of a stochastic optimization approach lies in the ability to define an objective of interest, in this case net economic benefits over the region, in a statistical sense. Crop production factors and environmental impacts, which define the net benefits, become random variables through their dependence on the random variation of aquifer properties. The best answer obtained from the analysis may thereby be interpreted with a known degree of confidence or risk

We have developed a simplified flow chart of the proposed optimization procedure in which the stochastic simulation model is embedded (fig. 2). An appropriate programming technique is used to determine values of irrigation and subsurface drainage rates at which the computed distributions of water table depth and salinity concentration will maximize the value of a statistically defined net benefit function of regional crop yield, artificial drainage, and irrigation management.

\section{Discussion}

Preliminary results from application of the optimization model using data from a region in the northeast portion of Westlands Water District have been encouraging. This is the only region known to have the extensive data on hydraulic conductivity, porosity, water table elevations, water table salinity, and cropping patterns necessary for the stochastic simulation model. Numerical experiments have indicated that degree to which uncertainty in predicted behavior of a saline water table depends on variability in aquifer properties and on regional irrigation uniformity.

Of more practical interest to agricultural production, it appears that uncertainty in net crop production is very sensitive to regional irrigation uniformity. Economic factors involved in improving uniformity while maintaining satisfactory leaching in the root zone are under investigation. It is hoped that this approach will continue to provide critical insight into regional management decisions necessary to address pressing salinity and drainage problems in the San Joaquin Valley.

Timothy $K$. Gates is post-graduate researcher, Department of Land, Air and Water Resources (LAWR), and PhD candidate in the Department of Civil En partment or Land Air and Water Resour ors (LAWR) neering, University of California, Davis; and Mark E.
Grismer is Assistant Professor, Department of Grismer is Assista
LAWR, UC Davis. 